\title{
Drain Site Abdominal Hernia: Known but Rare Complication of Abdominal Drains, a Case Report and a Review of Drain Site Complications
}

\author{
M B Samarawickrama ${ }^{1}$ R W Senavirathna ${ }^{2}$ U I Hapuarachchi ${ }^{3}$ \\ Senior Lecturer 1. Department of Anatomy, 2. Department of Surgery, 3. Department of Anaesthesiology \\ Faculty of Medicine University of Ruhuna Sri Lanka
}

\begin{abstract}
Drains are being used in abdominal surgery since Hippocrates time therapeutically and prohpylactically aiming to reduce morbidity and early recovery of patients. But these drains are not without complications. The complications range from simple drain site infection to drain site hernia of bowel leading to strangulation and necrosis. We report a case of drain site hernia (DSH) in a 47 year-old women who presented with obstructed large incisional hernia through a previous laparotomy scar. During surgery for the incisional hernia an incarcerated DSH was identified at her right iliac fossa region. Both herniae were repaired successfully and patient's recovery was uneventful. We reviewed the literature regarding the drain site hernia and other complications of abdominal drains. The article describes types of drains, their complications and predisposing factors for those complications and the steps to be taken for the prevention.
\end{abstract}

Key words: Abdominal Drains, Hernia, Complications, Predisposing Factors, Prevention

\section{INTRODUCTION}

Drains have been used in surgical practice since the time of Hippocrates in 460-377 BC. There are different types of drains which may be classified as open or closed drains. Drains are being used therapeutically or prophylactically to drain or prevent collection of fluid at surgical site and to facilitate healing. However these drains are not without complications which include ascending infections, erode in to abdominal viscera, evisceration of abdominal contents, perforation of a viscus, migration of drain and hernia through the drain site (drain site hernia). Drain site hernia (DSH) is a rare but a recognized complication of abdominal drains. Drain site hernia is considered as an incisional hernia which leads to early complications like obstruction and strangulations requiring emergency surgical interventions. Therefore the knowledge of presence of such problem and its predisposing factors are important in early identification and prevention of DSH and other complications of drains.

\section{CASE REPORT}

We encountered a case of drain site hernia complicated with incarceration of part of the omentum. The patient was a 47 year- old female who presented with abdominal pain, distension and vomiting for 3 days duration. After clinical assessment and investigations she was diagnosed to have an obstructed incisional hernia through the previous laparotomy incision. She had undergone an exploratory laparotomy for appendicular abscess in July 2000. During surgery there had been perforated appendix with large amount of pus in the peritoneal cavity. Routine closure of the abdomen was performed after peritoneal lavarge and appendisectomy. Corrugate rubber drainage (CRD) was inserted at right iliac fossa to drain the peritoneal cavity. Recovery was uncomplicated and she had been discharge from the hospital on $7^{\text {th }}$ postoperative day after removal of the CRD. She had noticed the presence of an incisional hernia through the abdominal incision several years after the surgery but without any symptoms until she presented this time with features of intestinal obstruction. She underwent an emergency surgery for repair of the incisional hernia and relieving of the obstruction. During surgery she was found to have large incisional hernia through the laparotomy incisions with multiple adhesions of the small bowel with obstruction. In additions to this there was a separate hernia at the right iliac fossa which contained omentum through the previous drain site. It contained part of the omentum and was irreducible, oedematous and there was serous fluid within the sac and it was an incarcerated drain site hernia. (Fig. 1) Both herniae were reduced. There were multiple defects throughout the laparotomy incision. Therefore mass closure of the rectus sheath was done after converting this multiple holes in to a single large laparotomy wound. The size of the defect at the drain site was more than $10 \mathrm{~mm}$ (Fig. 2) and that defect was closed with non absorbable sutures in layers. We did not use mesh to close the any of these herniae as there was wound contamination with intestinal contents due small bowel perforation during release of the multiple adhesions. Patient's recovery was uneventful. 


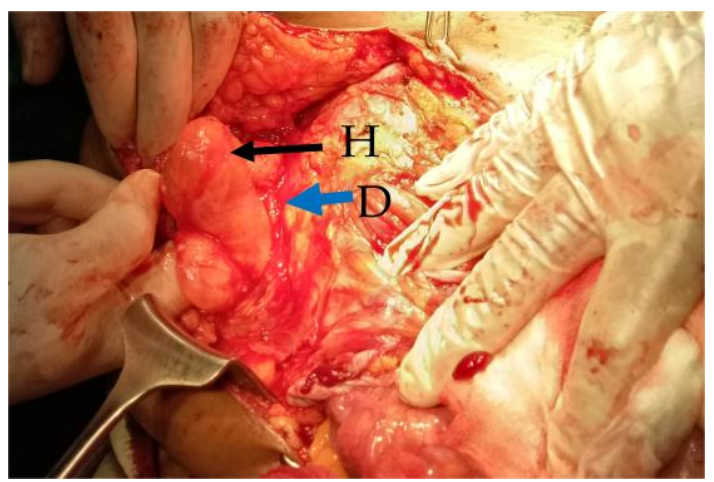

Figure 1: $\mathrm{H}=$ Drain site hernia $\quad \mathrm{D}=$ Defect in the abdominal wall

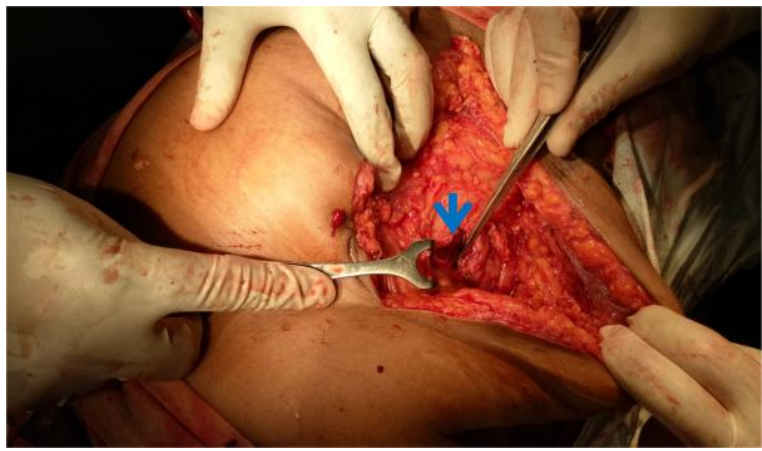

Figure 2: The defect at drain site after reduction of the hernia

\section{DISCUSSION}

1. Drains in abdominal surgery:

Use of drains in surgery is reported since the time of Hippocrates who used a drain tube to drain an empyema of the gall bladder [1]. Since then drains have been used in surgical practice for many purposes. Therapeutically abdominal drains are placed to drain the potential or established collection of blood, lymph, pus, bile, urine, pancreatic secretions or other body fluids [2][3]. It may be used prophylactically to prevent collection of blood or serous fluid at the surgical site. However drains cannot prevent complications like anastomotic leak or intraperitoneal bleeding. But it helps for early detection of such complications post operatively. However prophylactic drainage following routine abdominal surgery continues to be a controversial subject. Therefore the words of Halsted in 1898 might be more appropriate-'no drainage at all is better than the ignorant employment of it' than the dictum, 'when in doubt drain' (by Lawson Tait) [4].

\section{Types of drains:}

Since Hippocrates era to present day, surgeons are using different types of drains in abdominal surgery. Initially they used materials like gauze and silk threads to drain by capillary action. In 1880s tubes made up of metal, gold, silver and glass were used. Interestingly some surgeon have used different material like decalcified ox bone, poultry bone and skines of catgut [1]. Present day there are various types of drains available and they can be broadly divided in to open and closed drains. Open drains are directly open to both exterior and interior of the abdominal cavity. They drain both ways and are passive drains which are proven to be associated with contamination of the drain tract by retrograde spread of skin bacteria and not commonly been used now [5]. The drain that was inserted in our patient was a corrugated rubber drainage (CRD) which is a type of an open drain.

\section{Complications of drains:}

Several complications related to drains were encountered with the increase use of abdominal drains. Abdominal drains are commonly placed through the anterior abdominal wall but some have used vaginal route to insert drains to the pelvis. Keith (1864) introduced a transrectal peritoneal drainage after a pelvic surgery with disastrous results [1]. However the drains placed through the anterior abdominal wall is also not without complications. These complications include wound infections, drain site abdominal hernia (DSH), intestinal obstructions, formation of adhesions, fecal fistulae and persistent sinus tracts [1]. 


\subsubsection{Drain site hernia (DSH):}

Abdominal hernia is one of the common surgical problems and common types include inguinal, paraumbilical and incisional hernia. Incisional hernia occurs through previous abdominal surgical site. With the advent of laparoscopic surgery a newer type of hernia was identified as port site hernia. Similar type of hernia though rare has been reported to occur through abdominal drain sites that is known as drain site hernia (DSH). These latter two types can also be considered as small insicional hernia as they occur through a previous surgical wound.

Drain site hernia is found to occur more commonly in laparoscopic surgery than with open abdominal surgery. Makama J G et al. who studied 49 cases of DSH found that 42 of them were following laparoscopic surgery and the rest (7/49) of the DSH were at the site of drain following open abdominal surgery. This shows the rarity of this condition and the incidence of DSH is reported to be ranged from $0.14 \%-3.4 \%$ [6].

It is said that DSH occurs 3 - 8 hours after removal of the drain and Evangelos Falidas et al. described a case of DSH occurred 15 hours after a laparotomy [7]. However according to the Preetha Rani drain-site hernia commonly occur several months to several years following a laparotomy and are mostly associated with incisional hernias of the main laparotomy scar [5]. In our patient the diagnosis of the drain site hernia was made 16 years after the initial laparotomy and it also diagnosed during surgery for a large incisional hernia. The possibility was that the hernia in our patient may have been asymptomatic for a longer period and complicated with incarceration with obstruction of the abdominal incisional hernia. However, according to Gere S.diZerenga et al. the defect of the parietal peritoneum should last for about $72 \mathrm{hrs}$ as it takes about 3 days to heal a defect of $2 \times 2$ and $0.5 \times 0.5 \mathrm{~cm}$ size in the peritoneum [8]. Usually the peritoneal defect at a site of drain application is around this size. Therefore any abdominal structure can come through this defect up to $3^{\text {rd }}$ day of removal of the drain provided normal healing process take place. However this normal healing process will be affected by various factors which may delay healing or form weak scar tissue that predisposes to DSH [3] [7].

\subsubsection{Contents of DSH}

According to the Makama GJ et al. there are only very few incidence of DSH have been reported in the world literature. In each of these reported cases the contents are different from case to case. Those contents reported in the literature include small intestine, appendix, colon, omentum, gallbladder, ovary, and fallopian tube [3] [9] [10] [11]. Out of these structures the most commonly herniated abdominal viscera through a drain site were small bowel loops and appendix that may lead to obstruction or strangulation subsequently [5] [7]. Omentum is a common structure that is found in inguinal, incisional and paraumbilical hernia. But DSH with omentum as its content is reported to be very rare. Raju bakka et al. have reported the first DSH which contained the omentum in a post laparotomy patient [12]. We also could not find any other report except Raju bakka et al. case with omentum in a DSH. Therefore this is the second case of DSH contain omentum occurring in a post laparotomy patient. At the time of surgery the part of the omentum was incarcerated and irreducible with serous fluid surrounding and was impending strangulation. Because of the narrow neck this type of hernia tends to complicate with strangulation of its contents more than the other incisional hernia, inguinal hernia or paraumbilical hernia. Such case of DSH with strangulation of a loop of small bowel was reported by Evangelos Falidas et al [7]. Therefore the knowledge of occurrence of DSH is important for early identification and treatment to prevent such serious complications.

\subsection{Other complications of drains:}

DSH is not the only such serious complication occur due to drains. There are other disastrous complications of abdominal drains reported in the literature. A case of cecal perforation due to a silicon tube drain inserted to a patient after abdomino perineal resection, a case of perforation of the stomach by a drain tube inserted to left sub hepatic space after exploratory laparotomy for pyoperitoneum secondary to ruptured liver abscess and transmigration of a pelvic drain into loop iliostomy of a patient following low anterior resection for rectal carcinoma are some examples for such complications [10] [13] [14].

The other possible complications of abdominal drains include wound infection,induce anastomotic leakage (when inserted close to the anstomosis), haemorrhage, intra abdominal adhesions formations and intestinal obstruction (in long standing drains) bleeding perforation and fistula formation [3] [9] [10] [14]

\subsection{Predisposing factors for DSH and other complications:}

There are several predisposing factors for DSH stated in the literature. Out of these the size of the drain is a unique feature as all most all reported cases has occurred through a drain site defect of a size $10 \mathrm{~mm}$ or more [3]. However Dulkas A et al. described a case of port site hernia through a $5 \mathrm{~mm}$ port and Yogender Singh Kadian et al. reported a case of appendix evisceration through a $20 \mathrm{FG}(6.3 \mathrm{~mm})$ size drain site in a nine month old baby [9] [15]. Increase intra abdominal pressure is a known cause for any abdominal hernia. Similarly post operative cough, constipation and vomiting which increase intra abdominal pressure leads to DSH [3] [7] [9]. 
The factors that delay wound healing such as poor nutritional status, wound infection, certain drugs like steroid and chemotherapeutic agents, some comorbidities like diabetes mellitus, prolong surgery, obesity and injury to motor nerve are also known to cause DSH [3] [5] [7] [9] [12]. Direct stab on the peritoneum rather than allowing peritoneum to stretch and cut during insertion of the drain also predispose to hernia as the drain site wound directly continue with the external skin defect for the drain [3]. Our patient did not have any comorbidities and was average built. Therefore the size of the drain, direct stab on peritoneum and possible local infection may have been contributed to the DSH in our patient. Because she had corrugated rubber drainage which is usually inserted through a direct cut through the whole layers of the abdominal wall. There is a possible local sepsis although it is not stated in the medical report as the surgery was for appendicular abscess. The size of the drain is a definite cause for this patient's DSH as the defect was more than $10 \mathrm{~mm}$ as seen during surgery. Other complications like infections is commonly associated with open drains. Keeping a drain for a longer duration will leads to complications like perforations, fistular formation, adhesion formations, intestinal obstruction and drain migration [4].

\subsection{Prevention of complications:}

All the patients with an abdominal drain will not develop complications. Those who have predisposing factors are at high risk of developing DSH and other complications. Therefore the knowledge of predisposing factors are important when applying those preventive measures. One can prevent or reduce such complications by adherent to general principle in applying a drain and modifying or avoiding some known predisposing factors. Therefore the best way of preventing DSH and other complications is to avoid unnecessary placement of abdominal drains. This is especially important in insertion of a drain prophylactically. One should properly select the cases that essentially need drains because an experimental study showed that, when a drain is inserted in the peritoneal cavity that contains no fluids, it is quickly surrounded by omentum and completely occluded within 48 hours [15]. Therefore the purpose of the drain will be lost.

Prophylactic measures to prevent drain complications should apply at three stages. Firstly during selection of the appropriate drain, secondly use of correct technique during insertion and removal, thirdly remember to remove the drain as soon as it served the function.

Complications like infections are seen in open drains. Therefore it is advisable to use a closed system of drainage. Other complications like DSH and evisceration leading to strangulation are more with large caliber $(10 \mathrm{~mm})$ drains. Therefore, whenever possible use a smaller caliber drains. In a case of laparoscopic procedure use the $5 \mathrm{~mm}$ port site for the insertion of a drain [5] [9] [12] [17]. However if it is unavoidable in any specific reasons, apply a purstring suture when ever drain is taken through $10 \mathrm{~mm}$ port site [5] [17]. Some authors recommend in applying a pustring suture for the closure of the site after drain removal to prevent occurrence of DSH [7].

Many authors describe similar sort of technique to be used during insertion. They advice to insert the drain in a way that the skin and muscle layers are cut and pierced by the drain while allowing peritoneum to stretch and pierce at a different points so that the internal and external opening at drain hole placed at two different lines [5] [9]. Some authors describe this as non-symetric inserstion or a ' $Z$ ' insertion method [7]. This allows internal and external opening superimposed and closed when the drain is removed. Alternatively one can use the technique of gradual removal of the drain over a few days allowing the drain site to heal gradually from depth [9]. So that when the drain is out the drain site hole also closed. One must remember to remove the drain as soon as it served its purpose. This will prevent drain complications occurring due to long standing drains such as perforation of a viscera, migration of drain and adhesion formations [5].

\section{CONCLUSION:}

Insertion of a drain is a common procedure after many types of surgeries. Although its purpose is to minimize post surgical complications and morbidity of the patient it has its own complications increasing patient's morbidities. Therefore it is very important to know the presence of such complications and their predisposing factors so that surgeons can take measures to prevent certain disastrous complications.

\section{REFERENCES}

[1] Memon MA, Memon MI, Donohue JH. Abdominal Drains: a Brief Historical Review. Ir Med J 2001; 94:164- 166.

[2] Dr. Rahul Gupta, Dr. Ashok Kumar Gupta, Dr Dev Kumar Kasliwal, et al. Is Abdominal Drain a Double Edged Sword? SharmaIndian Journal of Basic and Applied Medical Research; March 2014: Vol.-3, Issue- 2, P.661-664

[3] A. G. Radhika, and Gita Radhakrishnan. Fallopian Tube Herniation: An Unusual Complication of Surgical Drain Lipi Sharma, Alpana Singh, Sruthi Bhaskaran. Case Reports in Obstetrics and Gynecology Volume 2012, Article ID 194350, 
[4] A. Loh and P.A. Jones. Evisceration and other Complications of Abdominal Drains Postgrad Med J (1991) 67, $687-688$.

[5] Preetha Rani Kumarprasad. Drain Site Hernias - A Rare but Recognized Complication of Surgical Drainage. A Study of their Risk Factors, Management And Prevention. University Journal of Surgery and Surgical Specialties Volume 3 Issue 22017

[6] Makama JG, Ameh EA, Garba ES. Drain Site Hernia: a Revive of the Incidence and Prevelance. West Afr J Med. 2015 Jan-Mar;34 (1):62-8.

[7] Evangelos Falidas, Stavros Mthioulaskis, Konstantinos Vlachos et al. Strangulated Intestinal Hernia Through a Drain Site. Int J Surg Case Rep. 2012; 3 (1): 1-2 PMCID:PMC 3267249

[8] Gere S. diZerega, Joseph D. Campaeu. Peritoneal Repair and Post-Surgical Adhesion Formation. Human Reproduction Update vol 7, No 6 pp 547-555 2001.

[9] Yogender Singh Kadian, Anjali Verma, Vikas Verma. Appendicular Evisceration via Drain Site - an Unusual Complication in a Child. International Journal of Contemporary Medical Research 2016;3(9):2720-2721.

[10] Vázquez-Ruiz J. et al. Perforación de Ciego Secundaria a Drenaje Quirúrgico. Reporte de Un Caso. (Cecal Perforation Secondary to Surgical Drainage a Case Report) Cirugía y Cirujanos. 2015; 83: 70-73. at http://www.elsevier.es/en-revista-cirugia-cirujanos-english-edition--237-articulo-cecal-perforationsecondary-surgical-drainage--S2444050715000157

[11] Jamadar, N.S., Saha, S., Mondal, S. et al. A Rare Case of Intestinal Obstruction: Herniation of Colon Through Drain Site. Hellenic J Surg (2016) 88: 439. doi:10.1007/s13126-016-0369-8.

[12] Raju bakka, Asho chinthamani,Nagaraju vubbana, Adarsh Paidi. Drain Site Hernia with Omentum as Content a Case Report and a Review of Literature. Medical Science vol 5, issue 7 july 2015.

[13] S Sahu, D Bahl, M Husain, P Sachan. Drain Erosion into Bowel: An Unsual Complication. The Internet Journal of Surgery. 2007 Volume 16 Number 2.

[14] Mehmet Karabulut, Murat Gönenç, Mehmet Abdussamet Bozkurt, et al. Rare Complication of Abdominal Drain: Transmigration of Drainage Tube into The DivertingLoop Ileostomy; Kolon Rektum Hast Derg, Aral>k 2011. At http://www.journalagent.com/krhd/pdfs/KRHD_21_4_187_190.pdf

[15] Dulskas A, Lunevicius R, Stanaitis J. A. Case Report of Incisional Hernia Through a 5mm Lateral Port Site Following Laparoscopic Cholecystectomy. J Min Access Surg [serial online] 2011 [cited 2017 Mar 3];7:187-9. Available at http://www.journalofmas.com/text.asp?2011/7/3/187/83512

[16] Marcello Picchio, Pierino Lucarelli, Annalisa Di Filippo. et al. Meta-Analysis of Drainage Versus no Drainage after Laparoscopic Cholecystectomy. JSL. October-December 2014 Volume 18 Issue 4. At https://www.ncbi.nlm.nih.gov/pmc/articles/PMC4266231/pdf/e2014.00242.pdf

[17] Gass M, Zynamon A, von Flüe M, Peterli R. Drain-site hernia containing the vermiform appendix: Report of a case. Case Rep Surg. 2013;2013:19 